\title{
Efeitos de Tratamentos Pré-Germinativos na Germinação de Chamaecrista dentata (Vogel) H.S. Irwin \& Barneby
}

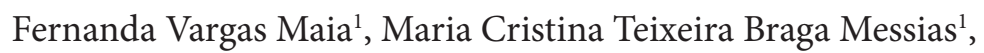 \\ Moemy Gomes de Moraes ${ }^{2}$ \\ ${ }^{1}$ Departamento de Ciências Biológicas, Universidade Federal de Ouro Preto - UFOP \\ ${ }^{2}$ Departamento de Biologia Geral, Universidade Federal de Goiás - UFG
}

\begin{abstract}
RESUMO
Chamaecrista dentata (Vogel) H.S. Irwin \& Barneby é uma leguminosa arbustiva endêmica da Cadeia do Espinhaço (MG) que apresenta forte vulnerabilidade por ocupar áreas sujeitas à grande impacto ambiental. Com o objetivo de verificar as condições mais propícias para a germinação de $C$. dentata, sementes recém-colhidas foram sequencialmente submetidas aos tratamentos pré-germinativos para avaliação de métodos de escarificação, influência da temperatura e da luz, isoladamente. As sementes apresentaram dormência física e a escarificação mecânica foi mais efetiva para superá-la. A incubação em 20 ou $25^{\circ} \mathrm{C}$ propiciou as melhores taxas e velocidade de germinação. As sementes mostraram-se neutras à luz.
\end{abstract}

Palavras-chave: dormência tegumentar, semente, Parque Estadual do Itacolomi.

\section{Effects of Pre-Germinative Treatments on the Germination of Chamaecrista dentata (Vogel) H.S. Irwin \& Barneby}

\begin{abstract}
Chamaecrista dentata (Vogel) H.S. Irwin \& Barneby is a leguminous plant species which is endemic throughout "Cadeia do Espinhaço", State of Minas Gerais, Brazil. It is an endangered species due to its occurrence in highly impacted areas. Aiming to verify the most appropriate conditions for the germination of Chamaecrista dentata, recently harvested seeds were sequentially treated for integument scarification, temperature and light influence, separately. Seeds showed physical dormancy which was effectively overcame by mechanical scarification. Incubation at 20 or $25^{\circ} \mathrm{C}$ was effective in promoting a higher germination rate and germination percentages. Seeds germinated either in light or in the dark.
\end{abstract}

Keywords: seed coat dormancy, seed, Parque Estadual do Itacolomi. 


\section{INTRODUÇÃO}

Chamaecrista dentata (Vogel) H.S. Irwin \& Barneby é uma leguminosa arbustiva que ocorre em áreas de campo rupestre, assim como em bordas de mata, capões e matas ciliares. Pode ser facilmente reconhecida por apresentar caule delgado e as folhas pêndulas, com à superfície brilhante $\mathrm{e}$ margem serrada (Dutra et al., 2008). Esta espécie produz flores e diásporos durante todos os meses do ano, sem apresentar um período com pico de floração e frutificação (Madeira \& Fernandes, 1999; Dutra et al., 2008).

Sua distribuição geográfica é restrita à porção sul da Serra do Espinhaço (Madeira \& Fernandes, 1999), ocorrendo desde a Serra do Cipó até a Serra do Itacolomi no município de Ouro Preto (MG). A espécie apresenta forte vulnerabilidade devido ao seu endemismo e por ocupar áreas sujeitas a grande impacto ambiental (Mendonça \& Lins, 2000).

Um dos aspectos do desenvolvimento vegetal que influenciam a distribuição das espécies é a germinação de sementes. Estes propágulos desempenham importante função ecológica na manutenção das populações vegetais e apresentam sua capacidade de germinar em limites bem definidos de fatores ambientais, inerentes a cada espécie, que caracterizam suas funções primordiais e sua distribuição geográfica (Rizzini, 1992). O comportamento germinativo das sementes pode evidenciar aspectos particulares dos locais e as condições preferenciais para o estabelecimento das plantas jovens numa comunidade (Ferraz-Grande \& Takaki, 2001). A germinação pode ocorrer de maneira bem distinta entre as espécies vegetais, considerando a interação com fatores do ambiente e os processos intrínsecos da semente.

A dormência é um fenômeno que pode influenciar a propagação sexuada. Sementes dormentes apresentam alguma restrição interna ou sistêmica à continuidade do desenvolvimento do embrião jovem e deve ser superada para ocorrer a germinação. Vários fatores podem determinar a dormência em sementes, como a impermeabilidade do tegumento à água e gases, imaturidade do embrião, presença de inibidores ou ausência de promotores de germinação ou exigências de luz ou temperatura (Bewley \& Black, 1994).

Existem diversas consequências da dormência de sementes para as populações e comunidades. Neste contexto, Bewley (1997) discute que a dormência é uma característica adaptativa que otimiza a germinação ao longo do tempo. Levine \& Murrel (2003) afirmaram que, quando aliada à competição e variações no habitat, a dormência pode ser mais importante que a dispersão para controlar os padrões de abundância relativa na comunidade. Portanto, a dormência possibilita a germinação e o desenvolvimento dos novos indivíduos quando as perspectivas do ambiente forem apropriadas; dessa maneira é uma característica adaptativa que melhora a distribuição temporal e espacial da germinação (Eira \& Caldas, 2000).

A ocorrência de dormência em sementes representa um paradoxo. Se por um lado aumenta as chances de sucesso no estabelecimento das plântulas de espécies nativas em ambientes não sujeitos à interferência humana, por outro é indesejável para as espécies cultivadas ou para a produção de mudas através de propagação sexuada, pois pode ocasionar a falta de uniformidade da emergência das plântulas e acarretar a necessidade de utilização de métodos para superação da dormência (Zaidan \& Barbedo, 2004). O conhecimento sobre a biologia e a reprodução é necessário para determinar a utilização de uma espécie em reflorestamento. Há, porém, carência de informações sobre as espécies tropicais nativas, inclusive para as espécies do gênero Chamaecrista (Bechara et al., 2007), o que dificulta a adoção de práticas conservacionistas ou de recuperação de áreas degradadas. Desse modo, tornam-se fundamentais os estudos sobre a germinação das sementes para a utilização e uso racional das espécies nativas.

C. dentata ocorre naturalmente em áreas sujeitas a adversidades, como a ocorrência de queimadas. Portanto, estudos sobre diferentes aspectos biológicos dessa espécie são imprescindíveis e necessários para fornecer subsídios à elaboração de planos de manejo para garantir sua preservação, além de estabelecer técnicas de propagação sexuada, contribuindo com propostas de revegetação de áreas degradadas que contemplem os locais de ocorrência natural dessa espécie. 
O objetivo deste trabalho foi o de verificar o efeito de tratamentos pré-germinativos na germinação de sementes de $C$. dentata, analisar a resposta da germinação à temperatura, a exposição à luz branca e determinar, de acordo com esses parâmetros, as condições mais efetivas que possibilitem a germinação de suas sementes.

\section{MATERIAL E MÉTODOS}

Chamaecrista dentata (Vogel) H.S. Irwin \& Barneby ocorre no Parque Estadual do Itacolomi, no Estado de Minas Gerais, nos municípios de Ouro Preto e Mariana entre os paralelos $20^{\circ} 22^{\prime} 30^{\prime \prime}$ e $20^{\circ} 30^{\prime} \quad 00^{\prime \prime}$ de latitude sul, e os meridianos de $43^{\circ} 32^{\prime} 30^{\prime \prime}$ e $43^{\circ} 22^{\prime} 30^{\prime \prime}$ de longitude oeste, abrangendo toda a Serra do Itacolomi pertencente à Cadeia do Espinhaço, Brasil. O parque apresenta como principais tipos vegetacionais as florestas estacionais semidecíduas, florestas de galeria, "candeiais", remanescentes de floresta de Araucária e campos quartzíticos e ferruginosos (Dutra et al., 2005). O clima na área, segundo a classificação de Koeppen, é do tipo Cwb, úmido (mesotérmico), ou seja, temperado úmido com inverno seco e verão quente e chuvoso. No período de março de 2001 a junho de 2002, a temperatura média mais baixa foi de $14,8{ }^{\circ} \mathrm{C}$ e a mais alta, $24,1^{\circ} \mathrm{C}$.

As sementes dessa espécie possuem 5-6 mm, são obovadas, plano-compressas e pontuadas com tegumento rígido de cor negra. Foram colhidas de frutos maduros ainda presos às árvores em diferentes matrizes de uma população do Parque Estadual do Itacolomi, em Ouro Preto (MG), no período de março a maio de 2002 e acondicionadas em frascos plásticos fechados em temperatura ambiente.

Para avaliar o melhor método de escarificação foram testados os seguintes tratamentos prégerminativos:

- Testemunha: sementes intactas;

- Escarificação mecânica, pela danificação do tegumento na região lateral da semente com auxílio de uma lixa para madeira número 150 até a visualização das estruturas internas da semente;

- Imersão em ácido sulfúrico concentrado por 5 minutos;

- Imersão em ácido sulfúrico concentrado por 10 minutos, ambos com posterior enxágue em água corrente por 90 minutos;

- Incubação em estufa a $70^{\circ} \mathrm{C}$ por 5 minutos;

- Incubação em estufa a $70^{\circ} \mathrm{C}$ por 10 minutos; e

- Incubação em estufa a $70{ }^{\circ} \mathrm{C}$ por 15 minutos; sendo os três pré-tratamentos térmicos seguidos de transferência imediata para geladeira $\left(10{ }^{\circ} \mathrm{C}\right)$ durante 30 minutos.

Depois de submetidas aos diferentes tratamentos, as sementes foram colocadas em placas de Petri previamente desinfestadas, com dois discos de papel de filtro umedecidos com água destilada e mantidas em germinador B.O.D. a $25{ }^{\circ} \mathrm{C}$ com iluminação constante. Foram utilizadas quatro repetições com 20 sementes por parcela. A protrusão de $2 \mathrm{~mm}$ de radícula foi o critério para considerar a semente germinada. Avaliações diárias foram feitas para verificar a germinação até a estabilização na porcentagem de germinação dos diferentes tratamentos.

A partir dos dados obtidos na primeira etapa, as sementes foram escarificadas e alojadas em placas de Petri como descrito anteriormente para a determinação da curva de embebição. As sementes foram analisadas periodicamente em balança analítica até não haver incremento significativo de massa. Para este ensaio, foram utilizadas quatro repetições com 10 sementes por parcela.

Para verificar a influência da temperatura, sementes de C. dentata foram escarificadas, colocadas em placas de Petri e alojadas em germinadores tipo B.O.D., nas temperaturas de $15,20,25$ ou $30^{\circ} \mathrm{C}$ sob iluminação constante, tendo o cuidado de manter o papel de filtro sempre úmido. Nessa análise, utilizaram-se quatro repetições com 20 sementes por parcela. A influência da luz foi avaliada em sementes submetidas à escarificação mecânica, incubadas na melhor temperatura, em placas de Petri envolvidas em papel alumínio e duas camadas de saco plástico preto, alojadas em germinador com luz fluorescente branca. Utilizaram-se quatro repetições com 20 sementes por parcela. A porcentagem de germinação foi avaliada após 7 dias do início do experimento.

Foram avaliados a porcentagem e o tempo médio de germinação por tratamento, sendo este calculado segundo Laboriau (1983), como descrito em Santana \& Ranal (2000). 
Para todos os experimentos foi utilizado o delineamento inteiramente casualizado. A análise da variância (ANOVA) e a análise de regressão foram realizadas utilizando o programa ASSISTAT 7.5. A normalidade dos dados foi verificada por diferentes testes pelo programa estatístico e, ao se detectar a falta de normalidade, os dados em porcentagem (x) foram transformados em arco seno $\sqrt{\mathrm{x} / 100}$. Após a análise de variância, as médias foram comparadas pelo teste de $t$ de Student a 5\% de probabilidade.

\section{RESULTADOS E DISCUSSÃO}

Sementes de Chamaecrista dentata submetidas a diferentes métodos para superação de dormência tegumentar apresentaram diferenças significativas $(\mathrm{p}<0,05)$ na porcentagem de germinação (Tabela 1$)$. A escarificação mecânica foi o método mais eficiente, resultando na maior porcentagem de germinação (85\%). Os outros tratamentos resultaram em menos de $50 \%$ de germinação, ainda que possibilitassem embebição de algumas sementes, verificada pelo aumento de volume. Os tratamentos térmicos a 10 ou 15 minutos promoveram as menores taxas de germinação, sendo maiores apenas que as das sementes sem escarificação, que não germinaram no período avaliado.

Tabela 1. Porcentagem e tempo médio de germinação de sementes de Chamaecrista dentata (Vogel) Irwin \& Barneby submetidas a diferentes métodos para escarificação. Ouro Preto, MG, 2002.

Table 1. Percentage and germination average time of Chamaecrista dentata (Vogel) Irwin \& Barneby seeds submited to different scarification methods. Ouro Preto, MG, 2002.

\begin{tabular}{|c|c|c|}
\hline Tratamentos & $\begin{array}{c}\text { Germinação }^{1} \\
(\%)\end{array}$ & $\begin{array}{c}\text { Tempo médio } \\
\text { (dias) }\end{array}$ \\
\hline Mecânica & $85,00(08,16)^{\mathrm{a}}$ & $1,63(0,28)^{\mathrm{a}}$ \\
\hline Térmico 5' & $42,50(27,54)^{b}$ & $4,36(0,97)^{c}$ \\
\hline Térmico 10’ & $7,50(5,00)^{\mathrm{d}}$ & $5,00(2,16)^{\mathrm{d}}$ \\
\hline Térmico 15’ & $15,00(4,08)^{\mathrm{cd}}$ & $3,77(0,98)^{\mathrm{bc}}$ \\
\hline Ác. sulfúrico 5’ & $25,00(10,80)^{\mathrm{bc}}$ & $4,18(0,50)^{c}$ \\
\hline Ác. sulfúrico 10’ & $41,30(11,09)^{\mathrm{b}}$ & $2,97(0,42)^{b}$ \\
\hline Testemunha & $0,00^{\mathrm{e}}$ & - \\
\hline \multicolumn{3}{|c|}{$\begin{array}{l}\text { Médias seguidas de letras distintas na coluna diferem entre } \\
\text { si pelo teste de } t \text { de Student a } 5 \% \text {. Desvio padrão está entre } \\
\text { parênteses }(\mathrm{n}=4) .{ }^{1} \mathrm{~A} \text { análise estatística foi realizada com dados } \\
\text { transformados em arco seno } \sqrt{\mathrm{x} / 100} \text {. }\end{array}$} \\
\hline
\end{tabular}

Além de propiciarem menores taxas de germinação, os tratamentos pré-germinativos térmicos e químicos aumentaram o tempo necessário para a germinação, verificado pelo aumento do tempo médio de germinação, quando comparado ao da escarificação mecânica, cujo tempo médio foi cerca de duas vezes menor que nos outros tratamentos (Tabela 1)

A massa média das sementes foi de $23,45 \mathrm{mg}$ ( $\pm 5,2 \mathrm{mg}$ ), valor próximo a $25,38 \mathrm{mg}$ encontrado por Gomes et al. (2001) para sementes provenientes de matrizes na Serra do Cipó, Minas Gerais. A análise da curva de embebição de sementes com tegumento lixado de $C$. dentata permitiu verificar que em 24 horas sua massa foi duplicada, enquanto sementes com tegumento intacto mantiveram sua massa constante durante o período analisado (Figura 1). Este dado reforça a característica da dureza do tegumento que, quando superada, permite a embebição e consequente germinação dessas sementes.

Os resultados obtidos estão em concordância com os de Gomes et al. (2001), que verificaram dormência tegumentar em 13 espécies do gênero Chamaecrista, incluindo C. dentata. Entretanto,

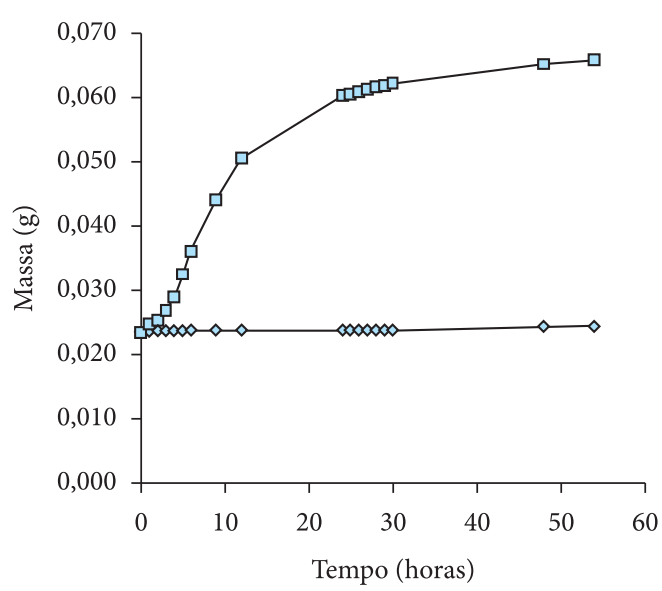

Figura 1. Incremento da massa das sementes de Chamaecrista dentata escarificadas com lixa (quadrado) e sem escarificação (losango). Ouro Preto, MG, 2002. $(\mathrm{n}=4)$.

Figure 1. Mass increase of Chamaecrista dentata seeds scarified with sandpaper (square) and without scarification (losangle). Ouro Preto, MG, 2002. ( $n=4)$. 
nesse gênero, pode haver diferenças na rigidez do tegumento. Em Chamaecrista flexuosa (L.) Greene, Bechara et al. (2007) verificaram que a imersão em água a $80{ }^{\circ} \mathrm{C}$ por 10 segundos resultou em maior porcentagem de emergência de plântulas, entretanto essa espécie deve possuir um tegumento com propriedades distintas do tegumento de C. dentata, pois sementes não escarificadas apresentaram $50 \%$ de emergência. Em outras sementes de leguminosas, como Bowdichia virgilioides Kunth, a dormência é mais bem superada utilizando imersão em ácido sulfúrico por 5 minutos (Smiderle \& Souza, 2003). A impermeabilidade do tegumento é característica frequentemente relatada para leguminosas (Rizzini, 1992; Medeiros \& Zanon, 1999; Cruz et al., 2001, Alves et al., 2004) como em Caesalpinia ferrea Mart. ex. Tul. (pau-ferro) e Mimosa caesalpiniifolia Benth. (Nascimento \& Oliveira, 1999), embora algumas espécies não precisem de escarificação para germinar, como as sementes de Cassia obtusifolia L. (Sy et al., 2001).

Tegumentos duros podem proteger o embrião do ataque de microrganismos (Eira \& Caldas, 2000) além de possibilitar que a germinação ocorra após a dispersão, caso a semente seja escarificada por ácidos do trato gastrointestinal de animais. Por outro lado, a rigidez do tegumento pode interferir na absorção de água, no alongamento do embrião, nas trocas gasosas e também impedir a saída de inibidores da germinação (Bewley \& Black, 1994). Segundo esses autores, o tegumento das sementes de leguminosas frequentemente atua impedindo a absorção de água, podendo prevenir a germinação por muitos anos. Essa impermeabilidade pode ser causada pela presença de uma cutícula cerosa, suberina e também a presença de células com paredes celulares muito espessas e lignificadas, como as células em paliçada e osteoesclereídes.

Considerando a baixa eficiência dos tratamentos com ácido sulfúrico e os riscos de sua manipulação, a escarificação mecânica do tegumento é o prétratamento mais recomendado para a germinação de $C$. dentata, assim como para outras leguminosas que apresentam este tipo de dormência (Sy et al., 2001), mas apresenta a limitação de ser dispendioso quando o número de sementes é muito grande, como sugerido por Nascimento \& Oliveira (1999).
No ambiente de ocorrência natural de $C$. dentata, a escarificação das sementes dessa espécie provavelmente ocorre por abrasão sobre o substrato arenoso ou rochoso, visto que foi observada síndrome de dispersão autocórica por torção valvar dos frutos.

A análise de regressão mostrou a influência da temperatura na porcentagem de germinação de sementes de $C$. dentata (Figura 2). Nas temperaturas 15,20 ou $25{ }^{\circ} \mathrm{C}$, a porcentagem de germinação foi semelhante. Na temperatura de $30{ }^{\circ} \mathrm{C}$, houve redução a quase metade da verificada nas outras temperaturas. Assim como a porcentagem de germinação, o tempo médio foi influenciado pela temperatura. Observou-se o retardo da germinação a $30{ }^{\circ} \mathrm{C}$ (Figura 3). Embora a incubação a $15{ }^{\circ} \mathrm{C}$ não tenha resultado em diferença significativa da germinabilidade, as sementes deste tratamento germinaram mais lentamente em comparação com as outras temperaturas testadas. As temperaturas 20 ou $25^{\circ} \mathrm{C}$ possibilitaram as maiores porcentagens e os menores tempos médios de germinação, portanto, nas condições deste experimento, constituíram as temperaturas mais adequadas para a germinação de C. dentata.

Segundo Sy et al. (2001), leguminosas tropicais têm temperatura ótima de germinação entre 30-35 ${ }^{\circ} \mathrm{C}$. Dalbergia nigra Allem, uma leguminosa da Mata Atlântica apresentou temperatura ótima de $30,5{ }^{\circ} \mathrm{C}$ (Ferraz-Grande \& Takaki, 2001). Sementes

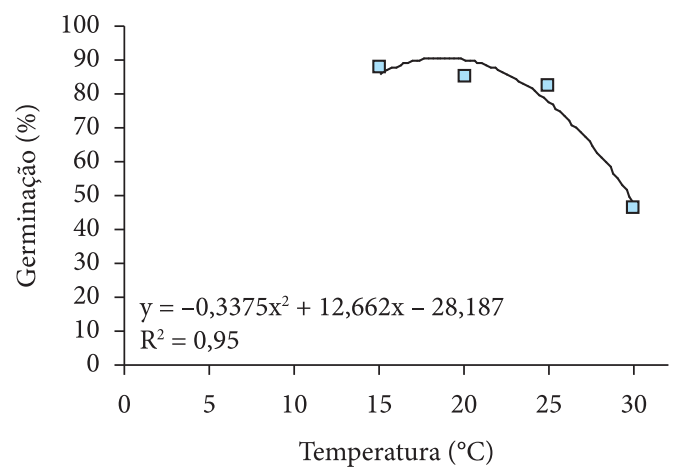

Figura 2. Influência da temperatura de incubação na porcentagem de germinação de sementes de Chamaecrista dentata escarificadas com lixa. Ouro Preto, MG, 2002.

Figure 2. Influence of incubation temperature on germination percentage of Chamaecrista dentata seeds scarified with sandpaper. Ouro Preto, MG, 2002. 
de Bauhinia forficata Link em ágar incubadas a $35^{\circ} \mathrm{C}$ sob luz mantêm sua porcentagem de germinação em 89\% (Rosa \& Ferreira, 2001). Estas temperaturas diferem da faixa de temperatura favorável à germinação de $C$. dentata, que foi de $20-25{ }^{\circ} \mathrm{C}$, enquanto a $30{ }^{\circ} \mathrm{C}$, temperatura ótima dos relatos anteriores, houve redução da porcentagem e do

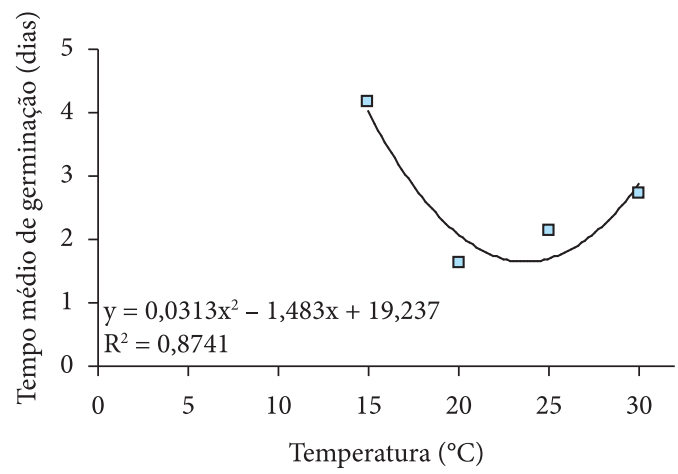

Figura 3. Influência da temperatura de incubação no tempo médio de germinação de sementes de Chamaecrista dentata escarificadas com lixa. Ouro Preto, MG, 2002.

Figure 3. Influence of incubation temperature on germination average time of Chamaecrista dentata seeds scarified with sandpaper. Ouro Preto, MG, 2002.

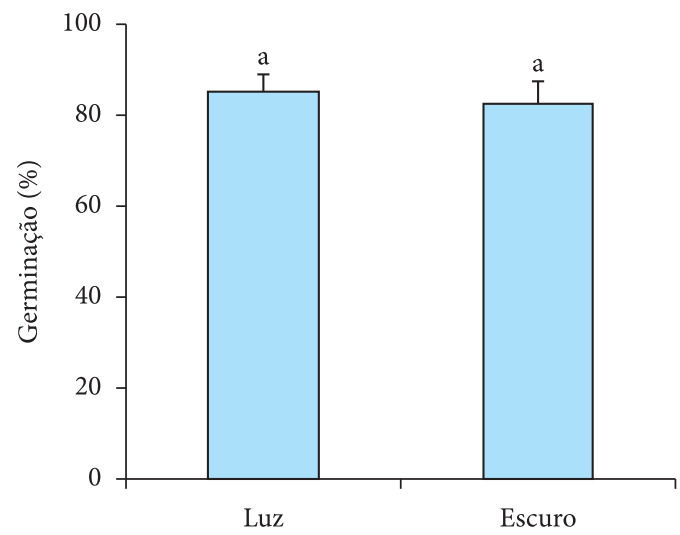

Figura 4. Germinação de sementes de Chamaecrista dentata, escarificadas mecanicamente, incubadas a $20{ }^{\circ} \mathrm{C}$ submetidas à luz ou escuro. Ouro Preto, MG, 2002. As barras representam o desvio padrão $(n=4)$. Médias rotuladas com a mesma letra não diferem entre si $(\mathrm{p}<0,05)$.

Figure 4. Germination of Chamaecrista dentata seeds, mechanically scarified, incubated at $20{ }^{\circ} \mathrm{C}$ and submitted to light or dark. Ouro Preto, MG, 2002. Bars represent standard derivation $(n=4)$. Means labeled with same character don't differ $(\mathrm{p}<0.05)$. tempo médio de germinação. Este comportamento com relação à temperatura está em concordância com as temperaturas médias registradas no Parque Estadual do Itacolomi em Ouro Preto, MG (14,8 e $24,1^{\circ} \mathrm{C}$ ), de onde foram coletadas as sementes usadas neste experimento.

Sementes com escarificação mecânica do tegumento submetidas a $20{ }^{\circ} \mathrm{C}$ foram neutras quando submetidas à luz branca, pois a porcentagem de germinação de sementes incubadas no claro e no escuro ao final de 7 dias, não foi estatisticamente diferente (Figura 4). Sendo neutra em relação ao requerimento por luz, C. dentata pode germinar tanto em locais abertos, a pleno sol, quanto em locais mais sombreados.

Observações adicionais indicam que, apesar da boa germinabilidade das sementes submetidas à escarificação mecânica e germinadas a 20 e $25^{\circ} \mathrm{C}$, as plântulas têm aspecto normal no início do desenvolvimento. No entanto, morrem em 1 até 10 dias após serem transplantadas para substrato coletado no local, sugerindo a exigência por outros fatores não analisados neste trabalho, como a interação com insetos (Silva et al., 2003) ou outros fatores bióticos, mas que devem ser estudados para a determinação dos planos de manejo da espécie.

\section{CONCLUSÕES}

Dentre os tratamentos pré-germinativos testados, a escarificação mecânica com lixa foi a mais efetiva para superação da dormência tegumentar das sementes de $C$. dentata. As melhores condições de incubação para promover a germinação das sementes foram as temperaturas de 20 ou $25^{\circ} \mathrm{C}$, na luz ou no escuro.

\section{AGRADECIMENTOS}

À pesquisadora Valéria Lúcia Oliveira Freitas da Fundação Centro Tecnológico de Minas Gerais (CETEC/MG) pela utilização da infraestrutura, e ao Engenheiro Alberto Vieira de Mello Matos, gerente do Parque Estadual do Itacolomi, pela autorização para a realização deste trabalho. 


\section{STATUS DA SUBMISSÃO}

Recebido: 30/10/2008

\section{AUTOR(ES) PARA CORRESPONDÊNCIA}

\author{
Moemy Gomes de Moraes \\ Departamento de Botânica, \\ Universidade Federal de Goiás - UFG, \\ CP 131, CEP 74001-970, Goiânia, GO, Brasil \\ e-mail: moemy@icb.ufg.br
}

\section{REFERÊNCIAS}

Alves AU, Dornelas CSM, Bruno RLA, Andrade LA, Alves EU. Superação da dormência em sementes de Bauhinia divaricata L. Acta Botanica Brasilica 2004; 18(4):871-879.

Bechara FC, Fernandes GD, Silveira RL. Quebra de dormência de sementes de Chamaecrista flexuosa (L.) Greene Leguminosae visando a restauração ecológica do cerrado. Revista de Biologia Neotropical 2007; 4(1): 58-63.

Bewley JD, Black M. Seeds physiology of development and germination. New York: Plenum Press; 1994.

Bewley JD. Seed germination and dormancy. The Plant Cell 1997; 9: 1055-1066. PMid:12237375. doi:10.1105/ tpc.9.7.1055

Cruz ED, Martins PO, Carvalho JEU. Biometria de frutos e sementes de jatobá-curuba (Hymenaea intermedia Ducke, Leguminosae- Caesalpinioideae). Revista Brasileira de Botânica 2001; 24: 36-41. doi:10.1590/ S0100-84042001000200005

Dutra VF, Garcia FCP, Lima HC. Caesalpinioideae (Leguminosae) nos Campos Rupestres do Parque Estadual do Itacolomi, MG, Brasil. Acta Botanica Brasilica 2008; 22(2): 547-558.

Dutra VF, Messias MCTB, Garcia FCP. Papilionoideae (Leguminosae) nos campos ferruginosos do Parque Estadual do Itacolomi, Minas Gerais, Brasil: florística e fenologia. Revista Brasileira de Botânica 2005; 28(3): 493-504.

Eira MTS, Caldas LS. Seed dormancy and germination as concurrent processes. Revista Brasileira de Fisiologia Vegetal 2000; 12 (especial): 85-104.

Ferraz-grande FGA, Takaki M. Temperature dependent seed germination of Dalbergia nigra Allem (Leguminosae). Brazilian Archives of Biology and Technology 2001; 44: 401-404. doi:10.1590/S151689132001000400010

Gomes V, Madeira JA, Fernandes GW, Lemos Filho JP. Seed dormancy and germination of sympatric species of Chamaecrista (Leguminosae) in a rupestrian field.
International Journal of Ecology and Environmental Sciences 2001; 27: 191-197.

Laboriau LG. A germinação das sementes. Washington, DC: Programa Regional de Desenvolvimento Científico e Tecnológico - OEA; 1983.

Levine JM, Murrell DJ. The community-level consequences of seed dispersal plants. AAnnual Review of Ecology, Evolution, and Systematics 2003; 34: 549-574. doi:10.1146/annurev.ecolsys.34.011802.132400

Madeira JA, Fernandes GW. Reproductive phenology of sympatric taxa of Chamaecrista (Leguminosae) in Serra do Cipó, Brazil. Journal of Tropical Ecology 1999; 15: 463-479. doi:10.1017/S0266467499000954

Medeiros ACS, Zanon A. Superação de dormência em sementes de acácia- marítima (Acacia longifolia) [online]. Colombo: Embrapa Florestas; 1999. Circular técnica, no. 32 [cited 2008 jul. 30]. Available from: http://www.cnpf.embrapa.br/publica/circtec/edicoes/ circ-tec32.pdf.

Mendonça MP, Lins LV. Lista vermelha das espécies ameaçadas de extinção da flora de Minas Gerais. Belo Horizonte: Fundação Biodiversitas e Fundação ZooBotânica de Belo Horizonte; 2000.

Nascimento MPSCB, Oliveira, MEA. Quebra da dormência de sementes de quatro leguminosas arbóreas. Acta Botanica Brasilica 1999; 13: 129-137.

Rizzini CT. Tratado de fitogeografia do Brasil. Aspectos sociológicos e florísticos. São Paulo: Hucitec; 1992. 2 vol.

Rosa SGT, Ferreira AG. Germinação de sementes de plantas medicinais lenhosas. Acta Botanica Brasilica 2001; 15(2): 147-154.

Santana DG, Ranal MA. Análise estatística na germinação. Revista Brasileira de Fisiologia Vegetal 2000; 12 (especial): 205-237.

Silva JAP, Ribeiro-Costa, CS, Johnson CD. Sennius Bridwell (Coleoptera, Bruchidae): novas espécies predadoras de sementes de Chamaecrista Moench (Caesalpinaceae) da Serra do Cipó, Santana do Riacho, Minas Gerais, Brasil. Revista Brasileira de Zoologia, 2003; 20(2): 269-277.

Smiderle OJ, Sousa RCP. Dormência em sementes de Paricarana (Bowdichia virgilioides Kunth - Fabaceae - Papilionidae). Revista Brasileira de Sementes 2003; 25(1): 72-75.

Sy A, Grouziz M, Danthu, P. Seed germination of seven Sahelian legume species. Journal of Arid Environments 2001; 49: 875-882. doi:10.1006/jare.2001.0818

Zaidan LBP, Barbedo CJ. Quebra de dormência em sementes. In Gerreira AG, Borghetti F, organizadores. Germinação: do básico ao aplicado. Porto Alegre: Artmed; 2004. p. 135-146. 